\title{
ÉTICA PÚBLICA E FORMAÇÃO HUMANA
}

\author{
Sidney Reinaldo da Silva*
}

\begin{abstract}
RESUMO: Neste texto, discuto, a partir da teoria da justiça, como as políticas sociais afetam a formação moral de um povo. Partindo do nexo entre ética pública e formação humana, analiso as tendências morais da concepção de "mínimo social": destaco a forma de ação pública correlata da concepção de justiça social, que se apresenta como receituário para as políticas sociais em sociedades reguladas pelo mercado. Critico a base moral das políticas sociais no Brasil, que propõem a autonomia dos indivíduos garantida pelo "mínimo social". Apresento um quadro de concepçôes de justiça social compatíveis com o capitalismo e as políticas públicas correlatas delas, tendo como contraponto a junção entre neoliberais e comunitaristas, entre autonomia da pessoa e responsabilidade social. Aponto impactos e impasses éticos-políticos, na formação humana, da submissão da política social no Brasil ao padrão neoliberal.
\end{abstract}

Palavras-chave: Formação humana. Ética pública. Política social.

\section{PUbliC ETHICS AND HUMAN FORMATION}

ABSTRACT: From the point of view of the theory of justice, this paper analyses how the social policies define the moral formation of a people. Based on the links between public ethics and human formation it defines the moral trends of the conception of the social minimum. It highlights the form of public action deriving from social justice, which is presented as a formulary for the social policies in free market societies. It then criticizes the moral basis of the Brazilian social policies which propose to guarantee individual autonomy through the social minimum. It presents some conceptions

* Professor do Programa de Pós-Graduação em Educação da Universidade Tuiuti do Paraná (UTP). E-mail: sreinald@uol.com.br

Educ. Soc., Campinas, vol. 27, n. 96 - Especial, p. 645-665, out. 2006

Disponível em <http://www.cedes.unicamp.br> 
Ética pública e formação humana

of social justice compatible with capitalism and the public policies they entail, and shows that neoliberalism and communitarianism have a similar conception of the role of public policies in the moral formation for individual autonomy and social responsibility. It eventually points out ethical-political impacts and impasses, for human formation, of fashioning the Brazilian social policies according to a neoliberal pattern.

Key words: Human formation. Public ethics. Social policy.

Introdução

$\mathcal{E}$ qual relation at the highst level favors, when life-prospects are involved, a social minimum based on an idea of reciprocity over one that only covers the human needs essential to a decent life. Here we see how the appropriete concept of a social minimum depends on the content of the public political culture, with in turn depends on how political society itself is conceived by its political conception of justice. The concept of the appropriate minimum is not given by the basic needs of human nature taken psychologically (or biologically) apart from any particular social world. Rather, it depends on the fundamental intuitive ideas of person and society in terms of wich justice as fairness is laid out. (Rawls, 2003, p. 132)

Este texto oferece elementos para a crítica das tendências das políticas sociais no Brasil. Estas têm sido marcadas por uma ambígua concepção de justiça, na qual se destacam as idéias de eqüidade, mínimo social, reciprocidade e responsabilidade social, cooperação e solidariedade, de modo a compatibilizar esses elementos com o mercado e a acumulação capitalista nos padrões mundiais recentes. Inicialmente, analiso os fundamentos morais da concepção liberal de justiça e seus impactos na política social. Mostro como o parâmetro do mínimo social molda a concepção de inclusão e o aspecto conservador dessa forma de enfocar a sociedade e as políticas públicas. Apresento um breve histórico das concepções de justiça compatíveis com o capitalismo e as políticas públicas correlatas delas. Finalmente, questiono as tendências da política social no Brasil frente a sua submissão ao padrão neoliberal, especialmente as que estão diretamente vinculadas à formação humana, e a concepção de autonomia dela correlata. 


\section{Ética pública e formação humana}

Ao se produzir ordem social, são criados padrões coletivos segundo os quais as pessoas são formadas. A política constitui-se no processo coletivo intencional de produção de ordem, de instituições sociais, no interior das quais os indivíduos são formados. A ética pública diz respeito às decisóes coletivas, às escolhas que pertencem a todos ou cujos efeitos atingem a todos (Veca, 1999, p. 5). Uma investigação no prisma da ética pública visa à forma pela qual as autoridades públicas repartem, no âmbito das decisões políticas, as vantagens ou desvantagens, os custos e os benefícios, os recursos e os direitos entre membros de uma coletividade. É tarefa de uma ética pública racional évaluer la politique, investigando a concepção de sociedade justa que a sustenta, bem como o critério ou conjunto de critérios que definem o que vem a ser o bem estar e os direitos das pessoas. A discussão da ética pública permite compreender as tendências da formação humana numa coletividade. Ambas expressam um mesmo padrão vigente de moralidade.

Nas sociedades capitalistas contemporâneas, o padrão que direciona as ações humanas, constituindo-se num imperativo, numa necessidade racional, é a lógica do capital, princípio de ação individual, coletiva e pública. É partir dela que são reguladas as atividades humanas. Assim, a moral é pensada como capital social e como tal deve ser formada. São as relações de mercado, a lógica dos negócios, o desenvolvimento de competências adaptativo-competitivas que definem os parâmetros éticos de formação humana, que estabelecem o que é ser autônomo.

Há, nas sociedades capitalistas recentes, um nexo entre ética pública e formação humana cuja análise mostra os fundamentos morais da concepção de "mínimo social", termo que indica o que cada pessoa necessita para ser considerada moralmente competente: autônoma. Esse mínimo define o que a sociedade deve proporcionar a todos, sem o qual uma pessoa perderia a capacidade de se inserir dignamente na vida coletiva, diga-se, no mercado. A concepção de mínimo social restringe o âmbito de ação do poder público. Assim, discutir as políticas sociais a partir da idéia de mínimo social é uma forma de investigar a concepção de justiça liberal.

O termo liberal é polissêmico e seus usos podem gerar uma série de confusão, uma vez que a "hegemonia liberal se manifesta de diversas maneiras" (Martins, 2003, p. 619). Defino a ética liberal como aquela 
em que está suposta a autonomia das pessoas como agentes individuais e racionais, em oposição às concepções que afirmam que semelhante autonomia não existe a não ser como produto do reconhecimento coletivo, fato indissociável da política, da cultura e da tradição. $\mathrm{Na}$ perspectiva econômica, a visão liberal opõe-se à concepção socialista da economia, sobretudo à idéia de controle social democrático (político) do mercado e da propriedade privada dos meios de produção, bem como da presença de um Estado interventor, empreendedor e capaz de alocar recursos para promover a justiça distributiva, no sentido de criar igualdade de condições sociais. Neste caso, o Estado, e não o mercado, é a esfera moral mais abrangente em que o reconhecimento recíproco das pessoas se efetiva, na forma de definição do que cabe a cada um. Como esfera moral, o Estado caracteriza-se na forma de uma intencionalidade coletiva, como uma vontade comum que se constrói politicamente.

\section{Ordem social e justiça liberal}

As instituições sociedades se configuram em padrões econômicos, culturais e ético-políticos. Esses padrões são correlatos de uma ordem historicamente construída. A ordem social pode ser chamada de "autogerada" somente no sentido em que ela resulta da atividade dos seres humanos, que são seres sociais, não sendo, portanto, definida por um ser supremo fora de nosso mundo, nem muito menos resultante meramente de nossas tendências biológicas, tais como se verificaria numa colméia ou num formigueiro. A ordem social é autogerada coletivamente a partir da produção e reprodução coletiva da existência humana. Essa empreita, transformando-se constantemente de acordo com as re-configurações da correlação de forças econômicas e ético-políticas, possui uma dimensão histórica radical, pois tudo está em um processo, em um "devir" contínuo. A história não dá saltos, nada acontece sem ter sido preparado, sem que condições específicas não tivessem possibilitado o advento do novo. A ordem social é construída historicamente e só é criticamente compreensível segundo a configuração das forças sociais em dado momento, o que pode ser investigado a partir da pergunta sobre a quem ela serve. Essas forças expressam o entrelaçamento das relaçóes de poder econômico, político, técnico-científico, comunicativo e bélico. Devido ao caráter instável da configuração e constituição social, nenhuma ordem, padrão de reconhecimento entre as pessoas, em relação ao qual se estabelece o 
que cabe a cada uma fazer, ceder, oferecer e receber, deve ser entendida fora do processo contraditório de destruição e criação de padrōes, da desordem que lhe é correlata, das ações que não se enquadram nos padrões de reconhecimento estabelecidos num determinado momento, mas que os tornam relativos.

O poder público tem-se definido como esquema de constrangimento, capacidade de definir prioridades para a coletividade, controle dos meios de produção e reprodução da existência social e dos meios de persuasão e de repressão. A sociedade é desigual porque a partilha do poder econômico gera diferenças históricas definidas pela divisão social do trabalho e da propriedade. Assim, a desigualdade de poder de consumo é apenas a ponta do iceberg da configuração das forças sociais, do processo histórico segundo o qual uma sociedade se constitui. A ordem expressa nas leis constitucionais que modulam juridicamente uma sociedade reflete e justifica a configuração de forças históricas, que define como os frutos da co-operação social são diferentemente apropriados.

A idéia de co-operação social, especificada pelo hífen, mostra que numa sociedade não há ninguém fora dela, a não ser os que não podem ser subsumidos pela ordem em questão, aqueles que não são determinados pelas suas relações de poder. Mas, frente à amplitude mundial da sociedade humana, em que o capital (produção, comércio, consumo, comunicação) integra todos os cantos da terra num vasto processo de expropriação e acumulação, dificilmente alguém estaria excluído da co-operação social. Cooperar significa operar juntos, seja no sentido cristão e comunista de cooperação e ajuda mútua, seja no sentido agônico de competição e mesmo guerra. Nesse sentido, vale o dito de que todo negócio é uma guerra e toda guerra é um negócio, pois os limites da co-operação, do operar juntos, são dados pelo que uns podem fazer dos outros, que tem como extremo a eliminação física do outro. Tal como o negócio e a guerra, a política é uma forma de co-operação. A co-operação não exige ou supõe necessariamente o entendimento, o acordo. Ela supóe alguma forma de contato, de estar envolvido numa configuração de poder, em um sistema de relaçóes, em que tudo se desloca e se intercambia. A concepção crítica de rede serve como um esquema para se pensar a co-operação e a forma como todos estão necessariamente em contato móvel. ${ }^{1}$

$\mathrm{Na}$ perspectiva pragmática do mercado, ainda que um mundo social ou cultural seja intraduzível para um outro, isso não significa a impossibilidade de se construir pontes entre eles. Sempre é possível estabe- 
lecer trocas de algum valor, mesmo que não haja entendimento. As trocas podem ser feitas mesmo quando não há um justo sistema de equivalência. Pode se trocar ouro por espelhos, como a história tem mostrado. $\mathrm{O}$ mundo humano envolve um vasto sistema de co-operação, mesmo que não haja entendimento cultural, lingüístico, político, econômico. Mesmo a guerra é uma forma de co-operar, de fazer coisas em conjunto, em que pessoas, grupos, classes e povos encontram-se dentro de uma certa configuração de força, que, neste caso, tende a resultar no esmagamento ou submissão total ou parcial do outro. O operar juntos é um imperativo da existência humana. Contudo, nem todas as formas de se operar juntos são aceitáveis e dignas de não serem combatidas. A questão central ético-política é a de como construir uma ordem social justa correlata a um processo de criar e partilhar valores co-operativos como base para a formação do ser humano.

A definição da forma justa ou injusta de co-operação se dá historicamente. No mundo social não há um fora, nem no tempo e nem no espaço. Nele entramos pelo nascimento e só saímos com a nossa morte. É a "natureza", um limiar instável da historia humana, que determina, inicialmente, as condições biológicas de nascimento e morte que nos incluem e excluem na sociedade. Mas as configurações da sociedade (nossas formas de produzir a existência, a cultura e a linguagem historicamente implicadas nela) perpassam nossa existência individual, que se dá no intervalo entre o nascer e o morrer. Desde o nascimento, já entramos na correlação de forças sociais. Estas são definidas pelas condiçôes históricas em que nascemos, vivemos e morreremos.

A questão básica é a de saber até que ponto o poder publico nacional pode controlar as condições de co-cooperação entre nós, de controlar o padrão de ordenamento das instituições sociais, que são estruturas nas quais as relaçōes de poder se expressam. $\mathrm{O}$ ordenamento da produção e da propriedade é dado por um padrão de co-operação, que define socialmente as formas válidas e inválidas de se produzir, apropriar, comercializar e consumir bens. Essa regulação tem sido modulada pelo mercado e/ou controlada pelo Estado, que se apresentam como duas fontes morais de regulagem social, ora compatíveis, ora incompatíveis.

Para os defensores do capitalismo, o princípio da eficiência do mercado é o definidor legítimo do padrão de justiça liberal. Segundo Nozick (1994), esse "padrão" expressa as formas válidas de aquisição e transferência de bens. Justa seria toda aquisição e transferência de bem feita se- 
gundo as normas tradicionalmente aceitas por uma sociedade liberal, não importando o resultado das transaçōes, ou seja, a concentração de riquezas e a desigualdade social geradas. Sendo assim, supõe Nozick, o capitalismo seria o melhor sistema, pois nele o padrão não resultaria de uma utopia imposta por uma parte da sociedade à outra. No capitalismo, terse-ia uma sociedade em que as pessoas "têm liberdades de se associarem voluntariamente para seguir e tentar realizar sua própria visão da boa vida na comunidade, mas onde ninguém pode impor [grifo do autor] sua própria visão utopista aos demais" (1994, p. 338).

Embora concorde com Hayek (1979) que toda tentativa de impor à sociedade um padrão de distribuição deliberadamente escolhida, seja ele uma ordem de igualdade ou desigualdade, seria inadmissível, Nozick acusa o seu colega na defesa do neoliberalismo de admitir ainda um padrão do que vem a ser o justo. Hayek admitiria que a distribuição deveria se dar de acordo "com os benefícios percebidos conferidos a outros". O pensador austríaco estaria propondo que a co-operação social não deveria distribuir conforme o mérito moral ou a necessidade, mas conforme "o valor das ações percebidas a serviço dos outros" (Nozick, 1994, p. 178). Para ambos os pensadores, o Estado tem que ser mínimo, sem o que ele perderia seu papel de guardiáo da ordem das aquisiçóes e trocas justas de bens.

Por seu lado, o liberalismo de Rawls recusa não só idéia de Estado mínimo, como também as desigualdades permitidas pelo Estado de bemestar social. Este, diz o autor, é um sistema que permite uma concentração de rendas inaceitável do ponto da justa distribuição. ${ }^{2}$ Rawls propõe que podemos e devemos estabelecer padrões de justiça para regular a estrutura básica da sociedade, o que só pode ser feito por meio de mecanismos institucionais que garantam uma redistribuição "eqüitativa" dos benéficos produzidos pela co-operação social. Seus princípios de justiça buscam garantir acesso a bens primários (renda, direitos, auto-estima etc.) e igualdade de oportunidades econômicas e políticas para todos, como elementos essenciais para uma sociedade bem ordenada. Para que isso ocorra, o poder público precisa intervir na estrutura básica da sociedade, visando restabelecer constantemente a eqüidade social, o que não é, para Rawls, incompatível com o mecanismo descentralizado do mercado.

Os pensadores de tradição marxista, por rejeitarem as bases do liberalismo econômico, apontam que qualquer forma de regular o capitalismo continuaria sendo injusta, por mais que ela avançasse no sentido 
de estabelecer a igualdade social (Mészáros, 2002, p. 305). O capitalismo deixaria sempre uma parte maior ou menor da sociedade excluída dos benefícios da co-operação social. Isto está inerente ao processo de acumulação do capital. A questão liberal é sempre a de justificar a existência dos menos favorecidos e definir o que a eles deve ser oferecido pela coletividade. Trata-se do debate em torno da definição do valor econômico e ético do mínimo social.

\section{A ética pública do liberalismo econômico}

O ideário liberal apresenta ora posições mais conservadoras, ora menos conservadoras em relação à desigualdade social e de como lidar com ela. Como defensores mais eloqüentes do ideário moral capitalista, Hayek e Nozick propóem o Estado mínimo e defendem que apenas o mercado efetivamente distribui, de forma justa, os bens produzidos pela co-operação social. Com isso, atacam a intervenção pública no mercado, alegando que os mecanismos políticos de redistribuição são injustificáveis do ponto vista ético. A ilegitimidade do Estado deve-se à idéia de que o poder público não seria isento, expressando um padrão ou utopia imposto por uma parte a outra da sociedade. Essa isenção ou falta de comprometimento ideológico e social com utopias ou ideários morais apresenta-se como o valor maior defendido pelo neoliberalismo. Nessa perspectiva liberal, somente o mercado deve ser decisivo na redistribuição dos bens sociais, pois o planejamento e medidas redistributivistas, por onerarem a propriedade privada, são vistos como ineficientes e totalitários. Já os pensadores liberais, que admitem a intervenção do Estado na economia no sentido de corrigir os efeitos "perversos" do mercado, tais como a concentração de renda e desemprego, são vistos como radicais em relação a certos valores básicos do capitalismo, na medida em que, de certo modo, tornam relativo o direito à propriedade. Contudo, esses autores apresentam-se também sempre comprometidos com a "estabilidade" do sistema capitalista, e com o restabelecimento de uma justiça supostamente inerente ao mercado. As tendências do poder público nas sociedades capitalistas, no sentido de atuar conforme uma visão mais ou a menos conservadora da ética pública liberal são correlatas das estratégias políticas para a garantia da "ordem" social capitalista.

A concepção moral inerente à tradição do liberalismo econômico supõe que a distribuição mais justa de recursos e bens é aquela que resul- 
ta da livre interação dos homens no mercado, e de que a desigualdade dela resultante deve ser aceita como o produto de uma harmonia natural ou equilíbrio das tendências econômicas inerentes ao jogo da oferta e da procura dado pela concorrência entre os agentes no processo de produção e troca. Isso seria natural e, portanto, ético. Para os liberais ultraconservadores, a naturalidade desse processo deveria ser aceita como justa qualquer que fosse o seu resultado. Malthus foi o maior defensor dessa moralidade natural.

Malthus (1963, p. 25) elabora uma ética fundada na natureza para justificar a desigualdade e a miséria. Nesse sentido, ele propõe a lei da população. Segundo esta, um agrupamento humano cresce em progressão geométrica: $1,2,4,8,16,32,64 \ldots$ e com uma rapidez muito maior do que o crescimento dos meios de subsistência, que se daria em progressão aritmética: $12,3,4,5,6 \ldots$. Ocorreria, portanto, um desequilíbrio entre os recursos naturais e as necessidades dos indivíduos, e o resultado seria a miséria de grande parte da população. Ele é pessimista em relação às condiçôes de progresso econômico e moral da humanidade. Para o autor, quem nasce num mundo já ocupado não tem direito a reclamar de nada. $\mathrm{O}$ mundo, lastima Malthus, é irremediavelmente drástico para os miseráveis. Para estes, não há lugar no banquete da natureza. Eles serão renegados pela própria essência das coisas. A natureza intima, define a sorte dos indivíduos, e não tarda a executar sua sentença. Assim seria justificado, pela própria necessidade brutal da realidade, o aumento da mortalidade devido à fome. De acordo com o autor, nada se poderia fazer para superar tais condiçôes. Qualquer solução pública para melhorar tal situação seria apenas um paliativo indevido.

Malthus justifica moralmente a miséria gerada pelo liberalismo econômico. Mas esse tipo de visão sombria do mundo liberal e da necessidade da miséria que ele gera foi questionado já por Adam Smith. Este autor não escreveu apenas um tratado sobre a economia, mas também sobre a moral. Sua defesa da ordem capitalista filia-se à tradição de pensamento moral iluminista.

Com os filósofos escoceses, durante o Século XVIII, surgiram novas teorias morais como parâmetros para a ação pública. É destacável, nesse contexto, a idéia de senso moral inato e comum. A concepção de uma faculdade moral específica apareceu na obra de Shaftesbury (16711713), intitulada Investigação sobre a origem de nossas idéias de beleza e virtudes, em 1725. Segundo esse autor, Deus proveu os seres humanos 
de um senso moral para se orientarem. Trata-se de um senso de beleza e de ação. Os juízos de valores fundar-se-iam nesse senso moral e não nas operações intelectuais. Nesta mesma linha de concepção da ação, o pensador Hutcheson (1694-1746) propóe que o senso moral humano é essencialmente altruísta. A suposição de um senso moral e estético preconiza uma espécie de harmonia moral que produziria um consenso a respeito da boa ordem social. Essa filosofia tornou-se uma base para o combate à concepção de indivíduo belicoso, que foi defendida por Hobbes.

É destacável também, no contexto dessas discussões de filosofia moral, o pensamento de Mandeville (1670-1733), nascido nos Países Baixos. Partindo da tese hobbesiana, ele visa provar o contrário do que propôs o autor do Leviatã. Conforme o texto Fábulas das abelhas, de Mandeville, publicado entre 1714 e 1729, o resultado da busca egoística do interesse individual, de forma surpreendente, beneficiaria toda a sociedade. Segundo a conhecida fórmula do autor, que aparece como subtítulo de sua obra, os "vícios privados" produziriam "benéficos públicos". Sendo assim, as paixões e os impulsos egoístas são os motores da economia. Portanto, não se deve reprimi-los para que se preserve a prosperidade social (Nicol, 1992, p. 16).

$\mathrm{Na}$ segunda metade do século XVIII, surge a filosofia moral de Adam Smith (1723-1790), que se tornou mais conhecido por sua obra no campo da economia. A sua Teoria dos sentimentos morais, publicada em 1759, foi complementada com as idéias desenvolvidas na obra $A$ riqueza das naçôes, aparecida em 1776. Nesta obra, as idéias de Mandeville são apropriadas para explicar a natureza do mercado. Contrabalançando ao egoísmo, concebido como o motor da ação econômica, Smith concebe, em sua obra sobre a moral, a idéia de simpatia. Com isso, o autor combate não só a tese hobbesiana do egoísmo como algo básico da natureza humana, mas também as concepçôes racionalistas da moral, para as quais a virtude depende meramente do conhecimento (Smith, 1992, p. 138 e ss.).

Segundo Smith (1992, p. 31), por mais egoísta que seja o ser humano, há algo nele que o levaria a se interessar pelo bem-estar dos outros, ainda que nada obtivesse a não ser o prazer da ação. A base desse sentimento de simpatia é a imaginação. Por meio dela, "nos colocamos no lugar do outro, concebemos estar sofrendo as mesmas dores, entramos, por assim dizer, em seu corpo, e, em certa medida, nos convertemos em uma mesma pessoa" (ibid., p. 32). Do sentimento de simpatia originária e da experiência de aprovaçãoo e reprovação de casos particulares 
de méritos ou deméritos, surgem regras gerais de condutas (ibid., p. 109110). A partir de tais regras, as próprias tendências perversas do amor próprio poderiam ser corrigidas (p. 111). A idéia de sentimento moral terá uma grande repercussão nas teorias morais do Iluminismo francês. Com Smith, a moral e a economia são reconciliadas: não haveria incompatibilidade entre egoísmo e o sentimento de simpatia. Assim, o autor forneceu uma justificativa moral para propor o liberalismo econômico como a melhor opção para a justiça e a prosperidade dos povos. Essa alternativa tem sido usada como contraposição ao pessimismo moral de Malthus. Os liberais não-malthusianos apresentam-se dispostos a aceitar alguma forma de ajuda aos miseráveis. O mínimo social ganha sua razoabilidade dessa benevolência moral, supostamente inata e universal.

A teoria do mínimo social está em completa sintonia com a tradição liberal. Mas não se trata de fazer justiça em nome do ideal moral substantivo. Nesse sentido, a proposta liberal já estaria presente em Locke, para quem cada indivíduo tem direito àquela porção da abundância de outrem, "que possa afastá-lo da extrema necessidade" (Martins, 2003, p. 645). No Brasil, devido às diretrizes dadas ao poder público, as políticas sociais tendem a manter a estabilidade do capitalismo e suas iniqüidades históricas, mantendo intactas as estruturas geradoras da concentração de rendas. A renda mínima, na medida em que é concebida conforme a tradição econômica liberal, distancia-se e atravanca a implantação de um beneficio formulado como um "embrião de uma renda universal socialista".

\section{Políticas públicas e formação do capital moral}

Com o fim da polaridade entre capitalismo e comunismo, tal como prevaleceu no período da Guerra Fria, as sociedades capitalistas intensificaram o processo de regulação segundo a lógica da eficiência, uma vez que não têm encontrado nenhuma força externa a elas forte o suficiente para barrá-las. Isso passou a ser princípio da ética pública. O resultado desse processo tem sido a expansão do modelo da administração privada para os setores antes sob o domínio da lógica do político e do princípio do interesse público. Com isso, divulga-se que a corrupção e a ineficiência do governo seriam substituídas pelo pragmatismo dos homens de negócios. Restaria ao governo manter as regras do jogo: garantir o direito de propriedade, a obrigação de assumir contratos "livremente" estabelecidos, especialmente aqueles referentes às transferências de pro- 
priedade e aos negócios. O governo também é incumbido da tarefa de zelar pela igualdade de oportunidades, e não apenas pela manutenção da livre concorrência.

Mas, frente à miséria decorrente da concentração intensificada de rendas, caberia ao governo promover políticas públicas para que a moralidade do capitalismo não se corroesse e, com isso, a estabilidade do sistema fosse ameaçada. Contudo, o governo deveria atuar segundo as regras dos negócios: evitar ao máximo possível taxar o "setor produtivo", ou seja, o lucro, e manter-se fiel aos acordos econômicos que, para os países endividados, significa pagar a dívida pública em dia. Isso inviabiliza os investimentos públicos nos setores que poderiam diminuir a miséria social de grande parte da população: saúde, educação, segurança, emprego, alimentação transporte, lazer etc. A saída encontrada foi o incentivo às atividades ligadas ao "terceiro setor", ao voluntariado e às atividades ligadas à responsabilidade social das empresas. Ao desincumbir o Estado de atuar de forma global, com planejamentos capazes de atacar frontalmente os mecanismos geradores da desigualdade social, a solução foi a de recorrer aos princípios econômicos e morais de Smith. Promover a benevolência, a solidariedade social sem, contudo, refrear a busca do lucro e o egoísmo. Assim, muitos trabalhadores são levados a participar de trabalhos voluntários para manter seu emprego que não é voluntário, cuja dedicação é necessária e vital. Mesmo estudantes e desempregados se envolvem em projetos de voluntariado para reforçar seu currículo ou suas chances de empregabilidade, como se isso formasse pessoas decentes para o mundo dos negócios.

Por seu lado, as empresas desenvolvem projetos com a finalidade de investir em programas de responsabilidade social, visando receber privilégios fiscais e legitimidade social. No capitalismo atual, o ideário smithiano parece se realizar: o egoísmo econômico e a simpatia ou solidariedade moral caminham de mãos dadas. A formação humana radical voltada para engendrar o combatente guerrilheiro ou o militante dos movimentos sociais vai dando lugar para a educação do voluntário. Assim se consolida a hegemonia do liberalismo atual.

O mínimo social, no discurso que justifica as recentes reformas do Estado no Brasil, possibilitaria a inserção do indivíduo numa ordem social já dada, operando como um mecanismo de equilíbrio entre os que mais ganham e os que menos ganham. Há quem veja nesse processo uma forma eficaz de se promover a justiça social no Brasil: 
Contrariando tendências recentes nas políticas governamentais, uma vez que elas vêm sendo ditadas ou pela questão do equilíbrio financeiro entre receita e despesa, ou pela focalização, sem as necessárias garantias para os componentes da eqüidade e da universalidade, o Programa Bolsa-Escola, ao articular a dimensão educacional com a renda mínima familiar, equilibra universalização com focalização. Isso porque promove uma política redistributiva, compensadora das enormes desigualdades promovidas pelo mercado, que expressam por sua vez a dimensão da pobreza estrutural. (Santos Junior, 2000, p. 33)

Contudo, frente a isso, o Estado perde sua centralidade, ganhando o estatuto reduzido de mero parceiro. Frente às atuais políticas públicas, em que o Estado torna-se o agenciador, avaliador e, direta ou indiretamente, financiador dos projetos e programas de assistência social terceirizados, prevalece a idéia de parceria entre os denominados primeiro, segundo e terceiro setores.

A política do salário mínimo, educação mínima, trabalho mínimo, expressa em bolsas disso e daquilo, revela um esforço para justificar a crueldade da desigualdade e da concentração de rendas. Mas, como no esquema da teoria dos jogos, o mínimo é correlato de um máximo. Se, na sociedade brasileira atual, o mínimo social revela a sensibilidade moral e a simpatia para com os pobres, ele também se articula com a garantia do máximo de lucro e acumulação das elites ligadas à classe proprietária dos meios de produção e capazes de fazer grandes negócios.

Conforme o princípio da reciprocidade da teoria da justiça liberal, que define a idéia de eqüidade, ninguém deve receber sem dar nada em troca. Disso resulta que algo é exigido dos miseráveis que recebem algum tipo de mínimo. Assim, exige-se que os beneficiados mandem suas crianças para a escola e, com isso, se possa garantir que elas recebam um mínimo de educação, alimento e cuidados. A eqüidade social, conforme a justiça liberal para os países "onerados", estabelece um critério eficiente (que não altera a lógica de acumulação e concentração de capital ou a suposta competitividade e estabilidade da economia nacional) para equacionar o mínimo que se pode exigir dos que ganham o máximo para evitar a "exclusão imoral" ou a morte à mingua de grande parte da população "desconectada" do "mercado" de trabalho e de consumo, que se tornou a única forma decente (autônoma) de se fazer parte da sociedade capitalista mundializada. A discussão mais séria tem sido a respeito de se distinguir um mínimo ridículo de um mínimo decente; um mínimo que 
gera dependência de um mínimo que produz autonomia, que possibilite a inserção das pessoas no "mercado". O mínimo social é correlato de um mínimo moral.

Segundo Rawls (2000, p. 204), as virtudes são uma forma de capital. Para ele, o termo capital é apropriado

(...) porque essas virtudes são constituídas lentamente com o passar do tempo e dependem não apenas das instituiçôes políticas e sociais existentes (elas próprias constituídas lentamente), mas também da experiência dos cidadãos como um todo e de seu conhecimento do passado. Repetindo: como capital, essas virtudes são depreciadas, por assim dizer, e devem se renovar constantemente, pela sua reafirmação e aplicação aos atos, no presente.

No âmbito da ética pública liberal, têm surgido recentemente diversas propostas e programas visando promover a saída das pessoas da miséria sem tutelá-las. Essas propostas giram, sobretudo, em torno da idéia de capital social. Trata-se de fazer com que a "sociedade civil" (terceiros setor, ONGs, igrejas, sindicatos e as mais diversas associaçōes) se "auto-organize" para que a miséria seja superada, a partir do desenvolvimento de atividades supostamente autônomas frente ao Estado e ao mercado. Isso estaria condicionado à capacidade do "capital social", na elevação da moralidade, da confiança mútua e da intensidade das parcerias entre os cidadãos. O capital, entendido como fator moral, como "social", se expressa na denominada cultura cívica. Para Putnam (1996, p. 125), que concilia comunitarismo político e liberalismo econômico, as reformas políticas, a descentralização, tendem a formar cidadãos participativos e autônomos, que não jogam as responsabilidades para o governo, e a gerar confiança mútua, honestidade e a observância da lei.

Assim, o capital moral é correlato do capital social e pode ser definido como a "argamassa que mantém as instituições em contato entre si e as vincula ao cidadão visando à produção do bem comum" (D’Araújo, 2003, p. 10). Desse capital depende a capacidade de associação e de "empreendimento" das pessoas. Ele se expressa nos vínculos sociais, na confiança mútua e na reciprocidade entre cidadãos. Redes de cooperação e empreendimentos associativos indicariam uma expansão do capital social. Como todo capital, quanto mais se aplica, mais se investe, mais ele teria chances de se acumular. Ainda que a teoria do capital social esteja ligada a pensadores críticos como Bourdieu (2003), ela encontra fervoro- 
sa defesa por parte de pensadores liberais doutrinários, como Fukuyama (1996). Nesse sentido, ela guarda uma ambigüidade política.

De qualquer forma, na teoria do capital social, a educação apresenta-se como um dos elementos decisivos na promoção humana. Acredita-se que seria "possível mudar hábitos e dinâmicas sociais de forma a produzir capital social, ainda que seja tarefa de décadas" (D’Araújo, 2003, p. 22). Ancorando-se nessa retórica, organismos internacionais de "cooperação" entre os povos, tais como o Banco Mundial, têm investido na educação da população de países "em desenvolvimento". Daí a íntima correlação entre desenvolvimento e educação como uma forma de se superar a miséria de modo autônomo. As tendências dessa proposta receberam uma profunda análise de Coraggio (2000). Para este autor, a autonomia se expressa na constituição de uma economia popular que rearticule atividades econômicas informais e amplie a capacidade cooperativa da população pobre, sobretudo, com investimentos econômicos criteriosos públicos e privados em ONGS voltadas para atividades cooperativas e educação popular. Isso seria então a base para o surgimento de sociedades eqüitativas e democráticas, onde antes prevaleciam a desigualdade, o autoritarismo e o paternalismo.

A proposta de Desenvolvimento Humano, promovida e em parte financiada pelo Banco Mundial e executada pelas ONGs, expressa a característica principal de um ideário de mínimo social correlato da desqualificação do Estado-nacional como agente coletivo integrado da promoção de políticas unificadas e universalizadas, como uma esfera autêntica de autonomia dos povos. O mínimo social é correlato do Estado mínimo, e de uma formação moral (ético-política) mínima. Dessa forma, equivocadamente se pensa em um desenvolvimento local sem a mediação e integração efetiva do Estado nacional como agente educativo e empreendedor.

Isso não deixa de ser uma forma alienante de promoção do desenvolvimento humano. Como lembra Vieira Pinto (2000, p. 53), o indivíduo alienado

(...) repele totalmente sua inserção em seus fundamentos histórico-nacionais e pretende resolver os problemas de sua sociedade, de seu mundo (em particular os problemas da educação) por meio de critérios e métodos que não foram extraídos de sua realidade, e sim recebidos de fora, venerados justamente por ter essa origem.

Assim, as atuais propostas de desenvolvimento local, ao partirem de uma concepção conservadora de sociedade autogerada, coadunam-se 
com o ideário moral liberal não-malthusiano de garantir um mínimo social para subsistência e estabilidade social com o neoliberalismo, que propõe o desenvolvimento como autogeração espraiada de empreendimentos e de desenvolvimento.

Contudo, as conseqüências morais dessa concepção de política social são incertas para os pobres. Estudos recentes têm apontado para o caráter moralmente contraditório dessas tentativas de "inclusão social" no Brasil. Fonseca (2001), em seu estudo sobre família e renda mínima, destaca que, para os pobres, a educação aparece como elemento fundamental para a melhoria das condiçôes de vida. Isso se vincula à legitimação dos programas de renda mínima, que exigem como contrapartida da família manter seus filhos na escola. Assim, as famílias pobres poderiam dispensar a contribuição econômica de suas crianças e seus adolescentes. Tais programas contribuiriam então para elevar os níveis de escolaridade dos descendentes e supostamente a empregabilidade dos mesmos. Contudo, os representantes das famílias pesquisadas estão conscientes de que, se existisse mais emprego para eles mesmos, não seria necessário programa de renda mínima. Assim, o trabalho é a aspiração mais forte dos responsáveis pelas famílias (Fonseca, 2001, p. 215). Nesse sentido, é destacável o anseio dos representantes das famílias por autonomia econômica que os possibilite dispensar os benefícios mínimos concedidos pelo Estado. Isso se coaduna com a ética liberal, para a qual esse tipo de dependência seria imoral, na medida em que constituiria uma forma de tutela pública de indivíduos, que passariam a ser um fardo para a nação e a carregar o estigma de incompetentes e incapazes. Esses fatores afetam a auto-estima e a dignidade da pessoa. Nessa situação de necessitada, ela não seria mais tomada como livre e igual de fato, em relação aos seus "concidadãos" que conseguiram se incluir no mercado e nele garantir sua subsistência e prosperidade.

$\mathrm{Na}$ impotência para mudar o modelo econômico, as políticas sociais do momento procuram amenizar as condições dos que estão "excluídos" com mínimos indecentes que os mantêm num limiar social entre ser assistido e ser autônomo, incluído no mundo do trabalho. Numa sociedade tão perversa como a brasileira, devido à histórica concentração de rendas, provavelmente as pessoas vão preferir contar mais com a certeza de serem assistidas do que com o desafio de se manterem autônomas. O governo de Lula tende a manter os miseráveis num limiar moral: ao receber o mínimo social do Estado, eles tendem a recusar a aventura no 
"mercado do trabalho". Apesar da intensa polêmica em torno das estatísticas oficiais, fica cada vez mais forte a convicção na sociedade brasileira de uma dramaticidade das políticas públicas. Nesse sentido, são interessantes as palavras de Lena Levinas, em entrevista concedida a Góes (2005), sobre o estudo de Álvaro Comin a respeito dos recentes dados da Pesquisa Nacional por Amostra de Domicílios (PNAD) do IBGE:

O mais grave é verificar que a renda dos mais pobres caiu mesmo com a participação dos programas de governo. Se esses dados forem consistentes, eles mostram que não estamos complementando a renda para os mais pobres viverem melhor, mas gerando uma renda para viverem quase que exclusivamente dela. Estão deixando de ser trabalhadores para se tornarem assistidos.

(...)

O pior desenho de política de combate à pobreza que a gente pode ter é justamente essa que condiciona o benefício a um nível de rendimento extremamente baixo. O beneficiado não pode ter mobilidade social porque, se aumentar sua renda, terá que abrir mão da bolsa. Como abrir mão de algo que é permanente para trocá-lo por algo instável?

A formação de pessoas típicas para um limbo moral, no presente governo, decorre do estilo liberal das políticas públicas, sobretudo da concepção de Bolsa-Família. Quem recebe o benefício do governo goza de uma autonomia perversa, afinal ele pode escolher entre mantê-lo ou não frente à possibilidade de mobilidade social. Contudo, no atual contexto social, a racionalidade o aconselha a recusar um trabalho precário e incerto frente à segurança da ajuda paternalista do Estado. Ele tende a escolher ser tutelado economicamente, o que é, paradoxalmente, inaceitável do ponto de vista liberal.

\section{Considerações finais}

A formação moral, quando pensada a partir da política pública, coloca em questão as possibilidades históricas de autonomia individual sem a autonomia nacional. Dentro da formação histórico-social do Brasil, isso se torna fundamental para se pensar as políticas de formação humana (social, econômica, cultural, política). Há questôes que não se calam. Retomo aqui algumas indagações feitas por Sanfelice em torno da autonomia do desenvolvimento nacional: 
Ética pública e formação humana

(...) existe a possibilidade de que países subordinados venham a ser autônomos? Existe a possibilidade de que uma cultura produzida de forma tendencialmente subordinada venha a se constituir em elemento significativo para a criação de condições favoráveis ao desenvolvimento e cultura autônomos? (1996, p. 123)

Não é ética e politicamente concebível a idéia de que uma nação subordinada em sua esfera mais ampla de Governo, na forma como se insere na economia mundial, bem como na gestão equivocada de sua produção científica e tecnológica, possa promover o desenvolvimento cultural e econômico de grandes setores populacionais historicamente reduzidas à miséria. Perante a forma como se dá a mundialização dos acordos econômicos, das leis, das condições do gerenciamento do capitalismo e dos valores liberais (ideológicas, práticas e disposições para agir, normas, concepções de mundo) que a acompanham, tem-se a ampliação da desigualdade e da subordinação entre os povos. Por tudo isso, "a forma mesma pela qual as sociedades subordinadas produzem seu próprio desenvolvimento efetiva-se também de maneira subordinada" (Sanfelice, op. cit., p. 122).

Vale a pena retomar uma idéia de Coraggio (2000) para encerrar esse texto. Segundo ele, os intelectuais atuantes nas ONGs, por não estarem dependendo dos calendários eleitorais, por atuarem supostamente fora da lógica política, podem contribuir não só "com opções de alta eficiência para manter certa prioridade quanto à perspectiva do desenvolvimento em escala global", mas também "contribuir para o uso eficiente dos recursos que possam ser obtidos, para obter uma crescente auto-suficiência nacional ou regional” (2000, p. 235). Contudo, inquieta ainda saber se é possível ou não cooperar com agências governamentais segmentadas, ONGs internacionais e bancos de desenvolvimentos em projetos conjuntos dirigidos aos setores populares, sem comprometer a autonomia desses agentes do desenvolvimento humano (2000, p. 159). Entretanto, o ponto mais decisivo é o da confiabilidade dos critérios autônomos de controle das ONGs, que tendem a prestar conta de resultados apenas em vista de obtenção e manutenção de financiamentos, segundo a lógica da produtividade e da eficiência.

É questionável, do ponto de vista da ética pública, pensar que o desenvolvimento humano de populaçóes pobres dependeria especialmente de um mínimo de capacidade de empreendimento que seria proporcio- 
nado pelas ONGs financiadas com dinheiro público e privado, que supostamente agiriam como uma faísca que, ao se espalhar, possibilitaria a tais comunidades se tornarem autônomas para se manter, gerando um processo mais amplo de desenvolvimento nacional sustentável com justa distribuição de rendas. Não haveria mais possibilidades de desenvolvimento autônomo - formação moral coletiva: ética, política e econômica - sem esse suposto Prometeu pós-moderno? Nada contra um agente que pudesse re/programar comunidades locais para se desenvolverem de modo autônomo. O que não se pode aceitar é que um governo empreendedor de políticas sociais de cunho universal e abrangente, capaz de promover e controlar atividades sociais e econômicas, combater a desigualdade social e ampliar a autonomia de toda uma coletividade, atrapalharia necessariamente o desenvolvimento local. A construção de um outro padrão de civilização, baseado na moralidade socialista democrática, depara-se com a transposição do limite crítico para se aceitar a retórica da despolitização dos movimentos sociais e da gestão pública. Essa transposição é uma tarefa da formação moral para uma "cidadania" moralmente combativa e não solidariamente resignada, como se vê atualmente.

Recebido em maio de 2006 e aprovado em junho de 2006.

\section{Notas}

1. "Se considerarmos a rede exclusivamente na sua acepção material, constatamos que ela pressupóe sempre móveis, o movimento e a deslocação de alguma coisa. No seio da rede, os móveis interpertencem-se num mesmo pacto vital baseado no intercambio reversível: os móveis devem poder circular nela de ponto a ponto" (Forget \& Polycarpe, 1997, p. 25).

2. "Such a sistem may allow large and inheritable inequalities of wealth incompatible with the fair value of the political liberties, as well as large disparities of income that violate the difference principle. While some effort is made to secure fair equality of oportunity, it is either insuficient or else ineffective given the disparities of wealth and the political influence they permit" (Rawls, 1999, p. XV).

\section{Referências bibliográficas}

BOURDIEU, P. Escritos de educação. Petrópolis: Vozes, 2003.

CORAGGIO, J. Desenvolvimento humano e educação. São Paulo: Cortez, 2000.

Educ. Soc., Campinas, vol. 27, n. 96 - Especial, p. 645-665, out. 2006 
Ética pública e formação humana

D' ARAÚJO, M. Capital social. Rio de Janeiro: Zahar, 2003.

FONSECA, A. Família e política de renda minima. São Paulo: Cortez, 2001.

FORGET, P.; POLYCARPE, G. A rede e o infinito. Ensaio de antropologia filosófica e estratégica. Lisboa: Instituto Piaget, 1997.

FUKUYAMA, F. Confiança: as virtudes sociais e a criação da prosperidade. Rio de Janeiro: Rocco, 1996.

GOES, A. Pobres se distanciam de ricos e dependem mais do governo. Folha de S. Paulo, São Paulo, 25 dez. 2005.

HAYEK, F. Law, Legislation and Liberty. London: Routledge \& Kegan Pau, vol. III, The Political Order of a Free People, 1979.

MALTHUS, T. First essay on population. New York: Reprints of Economics Classics, 1963.

MARTINS, C. Liberalismo: direito e avesso. Dados - Revista de Ciências Sociais, Rio de Janeiro, v. 46, n. 4, p. 619-660, 2003.

MÉSZÁROS, I. Para além do capital. São Paulo: Boitempo/unicamp, 2002.

NICOL, R. Introducción. In: SMITH, A. Teoria de los sentimientos morales. México: Fondo de Cultura Economica, 1992.

NOZICK, R. Anarquia, Estado e utopia. Rio de Janeiro: Zahar, 1994.

PUTNAM, R. Comunidade e democracia. A experiência da Itália moderna. São Paulo: FGV, 1996.

RAWLS, J. A theory of justice. Rev. Edit. Cambridge, Massachusetts: The Belknap Press of Harvard University Press, 1999.

RAWLS, J. O liberalismo político. São Paulo: Ática, 2000.

RAWLS, J. Justice as fairness. A restatement. Cambridge, Massachusetts; London: Harvard University Press, 2003.

SANFELICE, J.L. Subdesenvolvimento e cultura. In: MARCELINo, N.C. (Org.). Introdução às ciências sociais. Campinas: Papirus, 1996. 
SANTOS JUNIOR, O. Programa Bolsa-Escola: educação para a cidadania. In: Camarotti, I.; Spink, P. (Org.). Parcerias e pobreza. Soluções locais na implementação de políticas sociais. São Paulo: FGV, 2000.

SMITH, A. Teoria de los sentimientos morales. México: Fondo de Cultura Economica, 1992.

VECA, S. Ethique publique. Paris: PUF, 1999.

VIEIRA PINTO, A. Sete liçōes sobre educação de adultos. São Paulo: Cortez, 2000. 